\title{
Effectiveness of motor imagery for improving functional performance after total knee arthroplasty: a systematic review with meta-analysis
}

\author{
Ran $\mathrm{Li}^{1,2}$, Jubao Du ${ }^{1 *} \mathbb{0}$, Kun Yang ${ }^{1}$, Xue Wang ${ }^{1}$ and Wenjiao Wang ${ }^{1}$
}

\begin{abstract}
Background: The aim of this study was to appraise the effects of motor imagery on the functional performance improvement among total knee arthroplasty patients systematically. We hypothesized a relatively greater recovery in the motor imagery group.

Methods: Medline (Ovid), Embase and Cochrane Controlled Register of Trials (CENTRAL) were searched from inception to October 1st, 2021. We included randomized controlled trials evaluating the effects of motor imagery on the functional recovery among total knee arthroplasty patients. Measurements included range of motion, strength intensity, Visual Analogue Scale, Time Up and Go Test, Oxford Knee Score, Western Ontario and McMaster Universities Osteoarthritis Index, all of which were evaluated before and after intervention. Mean differences (MD) or standard mean differences (SMD) and 95\% confidence intervals (Cl) were calculated. The Cochrane risk of bias tool was used to assess the risk of bias.
\end{abstract}

Results: Six studies with 168 patients were included for the meta-analysis. The SMD of strength intensity was increased $(\mathrm{SMD}=0.90,95 \% \mathrm{Cl}=[0.47]-[1.32], P<0.001)$. The SMD of Visual Analogue Scale was reduced $(S M D=-0.91 ; 95 \% C l=[-1.29]-[-0.52], P<0.001)$. The SMD of Time Up and Go Test was reduced $(S M D=-0.56$, $95 \% \mathrm{Cl}=[-0.94]-[-0.19], P=0.003)$. The MD of Oxford Knee Score was slightly increased (MD $=0.79-$ point, $95 \%$ $\mathrm{Cl}=[-0.31]-[1.88], P=0.159)$. The outcomes of range of motion, Western Ontario and McMaster Universities Osteoarthritis Index were described according to the original data.

Conclusion: Compared with control therapy, motor imagery in the intervention group achieved an effective treatment for strength enhancement, pain reduction and physical activities improvement. More large-scale, prospective researches are needed in the future.

Trial registration: The PROSPERO trial registration number is CRD42021250996.

Keywords: Motor imagery, Total knee arthroplasty, Rehabilitation, Systematic review, Meta-analysis

*Correspondence: dujubaofei@163.com

${ }^{1}$ Department of Rehabilitation Medicine, Xuanwu Hospital, Capital Medical University, 45\# Chang Chun Street, Beijing 100000, China

Full list of author information is available at the end of the article

\section{Introduction}

Total knee arthroplasty (TKA) is a definitive therapy for progressively debilitating end-stage knee osteoarthritis [1]. As a golden standard, TKA is credible; however, the dissatisfaction ratio of patients has hit approximately twenty percent $[2,3]$. original author(s) and the source, provide a link to the Creative Commons licence, and indicate if changes were made. The images or other third party material in this article are included in the article's Creative Commons licence, unless indicated otherwise in a credit line to the material. If material is not included in the article's Creative Commons licence and your intended use is not permitted by statutory regulation or exceeds the permitted use, you will need to obtain permission directly from the copyright holder. To view a copy of this licence, visit http://creativecommons.org/licenses/by/4.0/. The Creative Commons Public Domain Dedication waiver (http://creativeco mmons.org/publicdomain/zero/1.0/) applies to the data made available in this article, unless otherwise stated in a credit line to the data. 
The dissatisfaction derives from a variety of reasons, among which, the functional improvement and pain alleviation usually are the key factors [3, 4]. Some studies showed that TKA resulted in a higher knee awareness even 12 months after surgery [5], and the knee function of most patients never restored to the level of agematched healthy population [6]. Moreover, severe pain after TKA caused a delayed postoperative recovery [7]. The traditional rehabilitation seems to provide limited efficacy for functional recovery. Castrodod et al. verified that high intensity and high velocity exercise were beneficial [8]. On one hand, post-TKA rehabilitation was encouraged to begin sooner rather than later [9], but on the other hand, early high intensity training would induce intense pain and consequent kinesiophobia [10]. It is critical to find a method which can both increase the training intensity early after surgery and improve the knee joint function without causing side effects. Motor imagery (MI) may have the potential to meet the requirements.

It was first reported as early as the 1940s that mental practice could improve the basketball performance and had the same effect as actual physical practice [11]. MI is a specific mental practice modality which refers to the mind rehearsal of a motor activity without body movements. It began to combine with rehabilitation at the beginning of the twentieth century and has been comprehensively studied so far. MI was widely used in neurological rehabilitation initially. Studies verified that MI was better in improving upper limb function and walking abilities among stroke patients [12, 13]. It was later found able to work equally well in musculoskeletal disorders rehabilitation. A systematic review showed that MI could provide a superior pain relief and greater range of motion among chronic musculoskeletal pain disorders [14]. MI also could ameliorate the knee flexion range and Western Ontario and McMaster Universities Osteoarthritis Index (WOMAC) performance in patients with knee osteoarthritis [15]. Besides the above preoperative effects, MI also performed well in postoperative recovery. Combining MI with action observation could reduce postoperative pain [16] and significantly improved the motor performance after hip replacement surgery [17]. Although MI needs no body movements, the cortical-spinal excitability and spinal transmission efficiency, which were specific to the imagined movement, increased during MI compared with during rest $[18,19]$. Therefore, the motor improvement might be due to more efficient motor unit activated by MI [20]. We postulate that MI is beneficial to the corresponding motor function without causing extra pain even during the early postoperative stage.

Recently, the applications of MI in TKA have been investigated through measuring range of motion (ROM), muscle strength, pain relief, and physical activities. Nevertheless, there were some inconsistencies among these research findings. The aim of this study was to clarify the role of MI in improving functional performance among TKA patients. We hypothesized a great improvement of strength enhancement, pain reduction and physical activities.

\section{Methods}

\section{Search strategy}

The Preferred Reporting Items for Systematic reviews and Meta-Analyses (PRISMA) statement was used for this systematic review and Meta-analysis [21]. The detailed PRISMA checklist was shown in Additional file 1. All co-authors agreed on the research protocol for this review before the systematic literature search was carried out by two independent authors (Xue Wang and Wenjiao Wang).

We conducted a systematic search of Medline (Ovid), Embase and Cochrane Controlled Register of Trials (CENTRAL), to identify relevant studies published in English from inception to October 1st, 2021. MeSH terms or keywords, such as "arthroplasty", "imagination", "TKA", and "knee prosthesis", were used to find relevant studies. We modified the search terms to optimize the search in each database. The reference lists of relevant included studies, reviews and meta-analyses were screened to identify relevant studies that might have been missed from the database search. We also contacted researchers when additional information was required.

\section{Selection criteria}

Studies that met all the following three inclusion criteria were included in the analysis: (1) All participants were aged between 45 and 85 years old. They were diagnosed as osteoarthritis and underwent a TKA surgery. (2) The experimental group was MI, and the control group was blank or a corresponding placebo treatment; physical therapy was routinely used in both groups. (3) The outcome measures included ROM, strength intensity, Visual Analogue Scale (VAS) and physical function.

Studies were excluded if the participants with a body mass index (BMI) greater than $40 \mathrm{~kg} / \mathrm{m}^{2}$; or the therapy was implemented during surgery.

Reviews, systematic reviews, meta-analyses, conference proceedings, clinical registration trials, abstracts and repetitive literatures were also excluded.

\section{Risk of bias assessment}

The risk of bias was assessed by two authors (Ran Li and Jubao $\mathrm{Du}$ ) with the method recommended by the Cochrane collaboration [22]. It contains seven items: selection bias (random sequence generation), 
selection bias (allocation concealment), performance bias (blinding of participants and personnel), detection bias (blinding of outcome assessment), attrition bias (incomplete outcome data), reporting bias (selective reporting), other bias (anything else). For each item, the authors judgement would be low, unclear or high risk of bias.

\section{Data extraction}

Two authors (Ran Li and Jubao Du) did the selection and data collection from the included studies independently. Article information included author name, publication year and country. Participant demographic information included sample size and average years. The intervention details included type of intervention, imagine content, imagine dosage, physical therapy dosage, control content (blank or placebo treatment as a comparison), control dosage, and experimental period. The outcome data included ROM evaluated by goniometer or electric goniometer, strength evaluated by dynamometer, pain evaluated by VAS, physical function evaluated by the Time Up and Go Test (TUG)/Oxford Knee Score (OKS)/WOMAC, pre-test and post-test timing for outcome measures, and results.

\section{Statistical analysis}

Meta-analysis was conducted only when the outcomes (strength, VAS, TUG and OKS) were judged by at least two studies; otherwise, systematic review was conducted (ROM and WOMAC). All the outcomes were continuous variables. When the outcome such as OKS was measured with the same scale across all the studies, mean differences (MD) with $95 \%$ confidence intervals $(\mathrm{CI})$ were calculated. Standard mean differences (SMD) with 95\% CI were calculated when the outcomes such as strength intensity, VAS and TUG were measured by different scales or methods. For the SMD effect size, $0-0.2$ was interpreted as meaningless, $0.2-0.5$ as a small significance, $0.5-0.8$ as a medium significance, and more than 0.8 as a large significance. We presented the results with forest plots. The meta-analysis was synthesized and analyzed using STATA 15.0 statistical software.

Heterogeneity among studies was assessed with $\mathrm{I}^{2}$ test. Statistical significance was considered when $P<0.05$. $\mathrm{I}^{2}>75 \%$ implied a considerable heterogeneity [22]. If $\mathrm{I}^{2}>75 \%$, data were pooled by the random-effects model. If $\mathrm{I}^{2} \leq 75 \%$, data were pooled by the fixed-effects model. We did not conduct the funnel plot and Egger test due to the limited number of included studies $(<10)$. Evidence credibility evaluation was discussed.

\section{Results}

Study selection

We obtained a total of 415 articles after the initial electronic database searching. After the duplicates were removed, 317 articles remained. After screening title and abstract, 304 articles not pertaining to our inclusion criteria were excluded. A total of thirteen articles were left for the full-text retrieval. Among these studies, seven were excluded because of the following reasons: one study used MI during surgery not after the TKA surgery; one study used guided imagery as the imaginary content; four studies used MI but the outcome evaluation was not consistent with our study; one study had only an abstract but no full-text. Thus, the remaining six studies were eligible. The flow diagram was presented as Fig. 1.

\section{Risk of bias assessment}

All the six studies were classified as "low risk of bias" for random sequence generation. Three out of six studies used randomized number or table while the other three studies used the block randomization. Only one study mentioned the allocation concealment and were judged as "low risk of bias". The other five studies did not mention the allocation concealment. All the six studies were judged as "low risk of bias" for performance bias. It was possible to mask the group allocation for routine rehabilitation therapist. The difference, however, was obvious between MI therapy and blank/conditional control therapy. This was the problem of the experiment itself. Two of six were classified as "high risk of bias" for detection bias. Testers were not blinded to group assignment because of inadequate financial support. One study did not mention the outcome assessment. One study was classified as "high risk of bias" for attribution bias because some patients were lost to follow-up and the drop-out data were not reported. We did not find other bias among all the six studies. The results were presented in Fig. 2.

\section{Study characteristics}

The characteristics of the included studies are listed in Tables 1 and 2. These studies were all completed in Europe (Italy and UK, Spain, Slovenia, France, France and Lebanon). The publication years were from 2017 to 2020. There were 168 participants in the 6 studies. The average age was between 45 and 85 years old. During the routine physical therapy, the intervention group was treated with MI, while the control group with a blank control or placebo treatment. The content of MI could be knee flexion and extension, muscle contraction, performing or imitating the function activity. The MI treatment time ranged from 13 to $30 \mathrm{~min}$ and lasted from 5 days to 4 weeks. The routine physical therapy time ranged from 30 to 


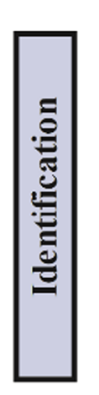

Records identified through electrical

database searching with keywords

(Medline, Embase and Cochrane

Controlled Register of Trials)

$(\mathrm{n}=415)$

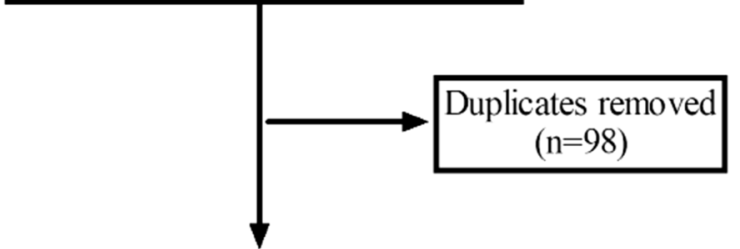

Records after duplicates removed

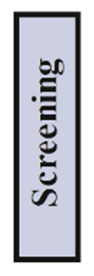

$(\mathrm{n}=317)$

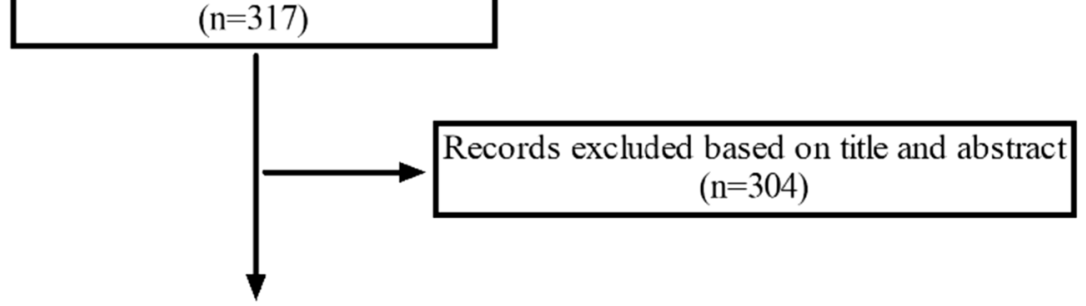

Full-text articles assessed for eligibility

$$
(\mathrm{n}=13)
$$
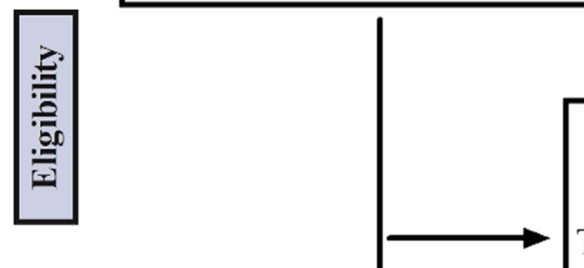

Records excluded based on full-text $(n=7)$

MI was used during surgery $(\mathrm{n}=1)$

The content of imagination waas guided imagery $(n=1)$

Did not assess the outcomes of our study $(n=4)$

Study did not exist $(\mathrm{n}=1)$
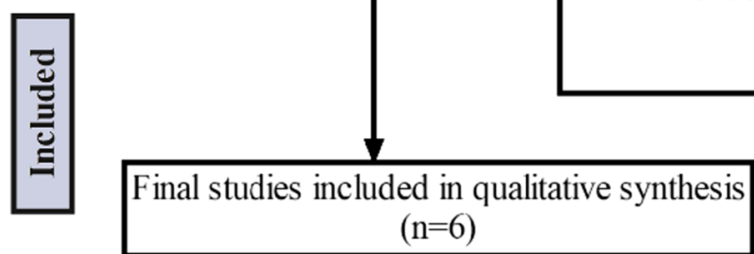

Fig. 1 A flow diagram showing the selection of included studies. Ml=motor imagery

70 min and lasted from 5 days to 4 weeks. The condition control was explicit world-news discussion, free discussion or non-motoric cognitive functions. The treatment time ranged from 15 to $30 \mathrm{~min}$ and lasted from 11 days to 4 weeks. As for the multiple outcome measures, the ROM of knee assessed by goniometer or optoelectronic system was used in five studies[23-27], knee strength assessed by dynamometer was used in four studies[24, 26-28], pain assessed by VAS was used in four studies[23-26], the TUG was used in four studies[24-27], the OKS was used in 2 studies [24, 27], and the WOMAC was used in 1 study [23].

\section{Outcome analysis}

\section{Effect of MI on ROM}

Five studies [23-27] measured the knee ROM that was evaluated by goniometer in the intervention group and control group among TKA patients. However, two studies $[24,26]$ focused on the knee flexion and extension ROM, one study [23] measured the knee flexion-extension ROM and showed the difference after subtraction directly, two studies [25, 27] referred to the peak knee flexion during the swing phase. Among them, and two studies suggested that the knee ROM cannot further increase after the intervention with MI; three studies 


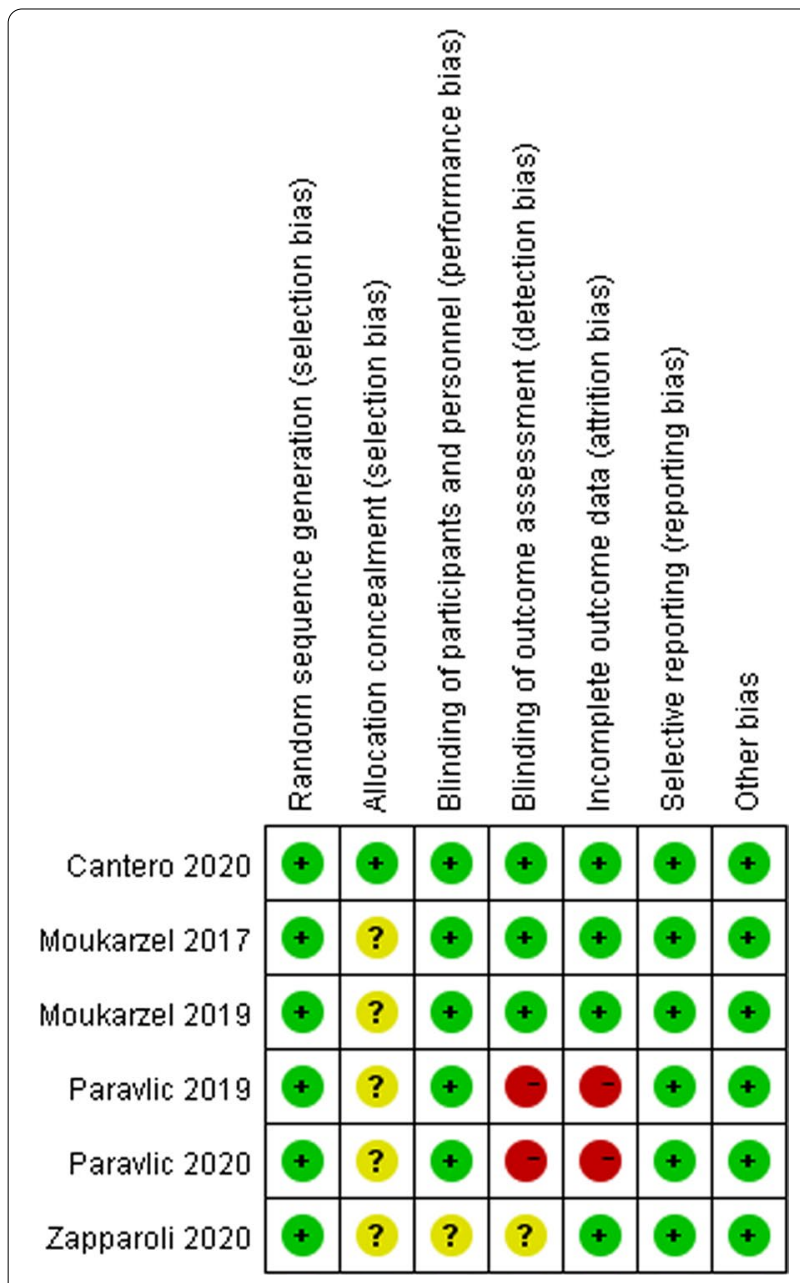

Fig. 2 Summary of risk of bias of included RCT studies

proposed that the intervention group with MI exhibited a larger gain in knee ROM.

\section{Effect of MI on knee strength}

Four studies [24, 26-28] comparing the knee strength outcome between the intervention group and control group were included for the meta-analysis. The effect size $(\mathrm{SMD}=0.90,95 \% \mathrm{CI}=[0.47]-[1.32], P<0.001)$ showed a significant increase of knee strength in favor of the intervention group with $\mathrm{MI}$ with a low level of heterogeneity $\left(P=0.251, \mathrm{I}^{2}=26.8 \%\right)$. The forest plot was presented as Fig. 3.

\section{Effect of MI on pain}

We performed a quantitative meta-analysis in four studies [23-26] that assessed pain with VAS between the intervention group and control group. Compared with the control group, the administration of MI in the intervention group resulted in a greater pain reduction
$(\mathrm{SMD}=-0.91 ; 95 \% \mathrm{CI}=[-1.29]-[-0.52], \quad P<0.001)$. According to the Cochran's Q statistical test $(P=0.259$, $\mathrm{I}^{2}=25.4 \%$ ), we observed no evidence of significant heterogeneity. The forest plot was presented as Fig. 4.

\section{Effect of MI on TUG}

When comparing the difference between the intervention group and control group, four studies [24-27] assessed the functional activity with TUG. A meta-analysis showed that there was an obviously TUG reduction in the intervention group with $\mathrm{MI}(\mathrm{SMD}=-0.56$, $95 \% \mathrm{CI}=[-0.94]-[-0.19], P=0.003)$. According to the Cochran's $\mathrm{Q}$ statistical test $\left(P=0.042, \mathrm{I}^{2}=63.4 \%\right)$, the heterogeneity was statistically significant. The forest plot was presented as Fig. 5.

\section{Effect of MI on OKS}

OKS was evaluated by two studies [24, 27] in the intervention group and control group among TKA patients. A meta-analysis showed that there was a slight improvement in the intervention group with $\mathrm{MI}(\mathrm{MD}=0.79$ point, $95 \% \mathrm{CI}=[-0.31]-[1.88], \quad P=0.159)$ but no statistical significance. According to the Cochran's Q statistical test $\left(P<0.001, \mathrm{I}^{2}=91.8 \%\right)$, the heterogeneity was statistically significant. The forest plot was presented as Fig. 6.

\section{Effect of MI on WOMAC}

Only one study [23] observed the WOMAC. TKA patients in the intervention group with MI had a lower WOMAC value compared with the control group. That was to say, TKA patients with MI experienced greater improvement in pain and pain-related disability.

\section{Discussion}

The main findings of this study were that MI in the intervention group was effective in strength enhancement, pain reduction and TUG decrease among the TKA patients. There was a slight OKS improvement in the intervention group with MI but no statistical significance. Because of the inconsistent outcome measures of ROM and the limited study number of WOMAC, we could not give quantitative results definitively. Our analysis suggested that MI may have great potential for improving the prognosis of TKA.

In our study, knee strength was significantly enhanced in the intervention group with MI compared with the control group. Previous systematic review and metaanalysis showed that MI group had advantages on maximal voluntary strength in healthy adult populations compared with the control group without any exercise [29]. An umbrella and mapping review with meta-metaanalysis tried to investigate the effect of MI and action 


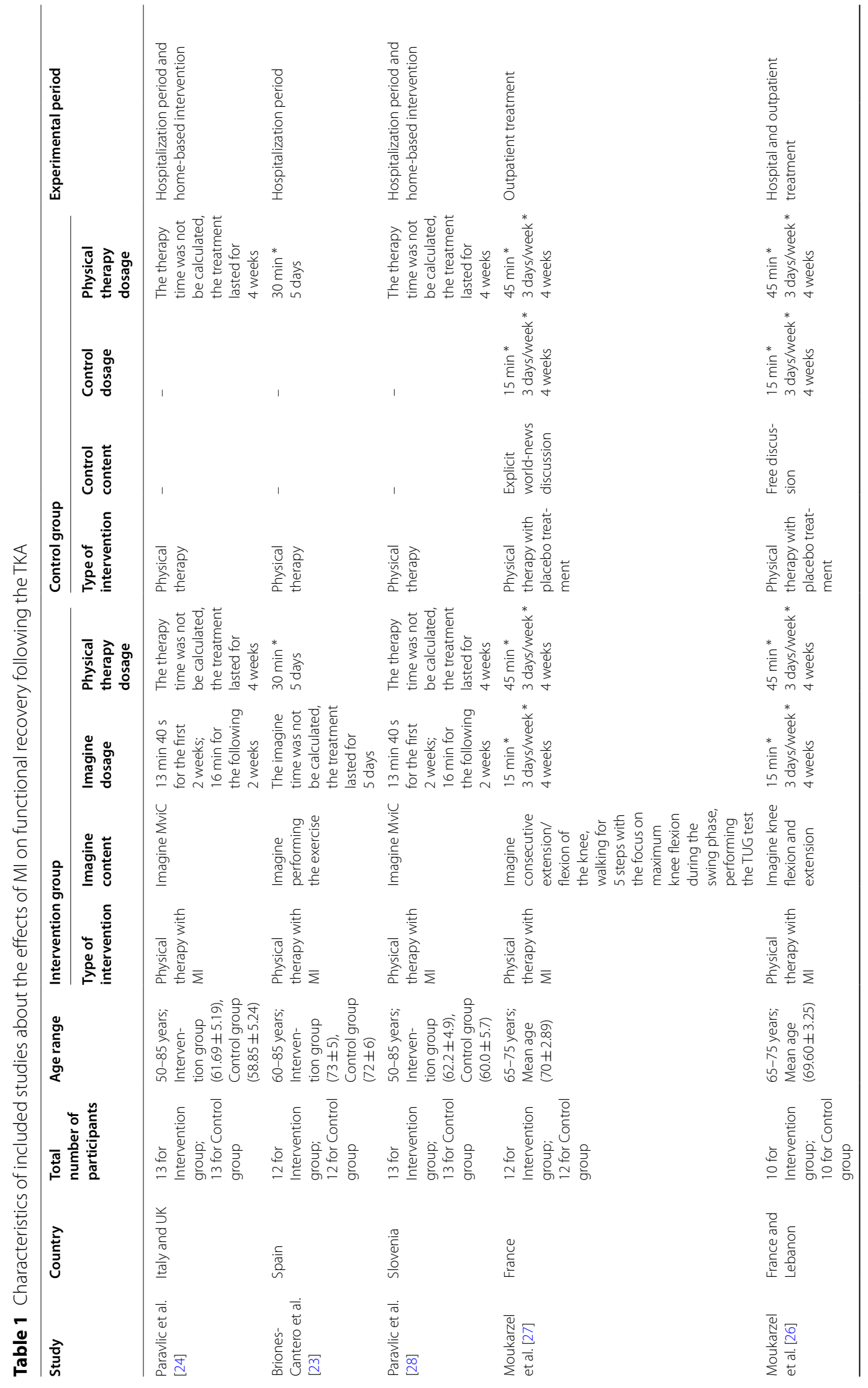




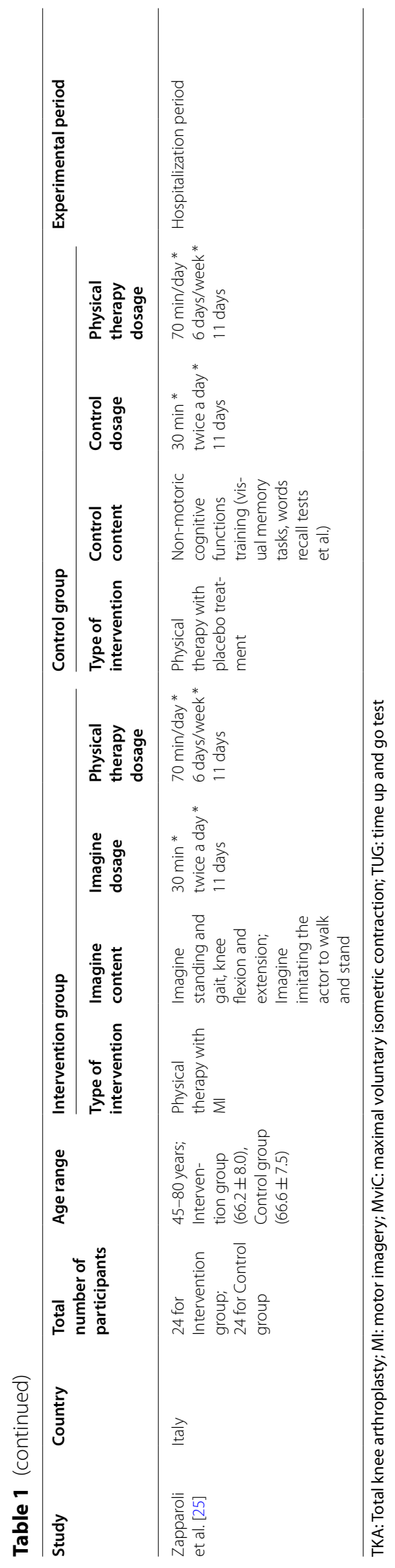


Table 2 Outcome measurements for each study included in this meta-analysis

\begin{tabular}{|c|c|c|c|c|c|}
\hline Study & Country & Outcome measures & Outcome units & Assessment timing & Results \\
\hline Paravlic et al. [24] & Italy and UK & $\begin{array}{l}\text { Pain evaluated by VAS; } \\
\text { Knee strength; } \\
\text { Knee flexion and exten- } \\
\text { sion ROM; } \\
\text { TUG; } \\
\text { OKS }\end{array}$ & $\begin{array}{l}\text { VAS (0-100): points; } \\
\text { Knee strength: Nm/kg; } \\
\text { ROM: degrees; } \\
\text { TUG: seconds; } \\
\text { OKS score: points }\end{array}$ & $\begin{array}{l}\text { Pre-test: } 1 \text { day before } \\
\text { TKA; } \\
\text { Post-test: } 1 \text { month after } \\
\text { TKA }\end{array}$ & $\begin{array}{l}\text { VAS } \rightarrow \text {; } \\
\text { Knee strength } \uparrow ; \\
\text { Knee flexion and exten- } \\
\text { sion } R O M \rightarrow \text {; } \\
\text { TUG } \downarrow ; \\
\text { OKS } \uparrow\end{array}$ \\
\hline $\begin{array}{l}\text { Briones-Cantero et al. } \\
\text { [23] }\end{array}$ & Spain & $\begin{array}{l}\text { Pain evaluated by VAS; } \\
\text { ROM; } \\
\text { Short-form WOMAC }\end{array}$ & $\begin{array}{l}\text { VAS (0-100): points; } \\
\text { ROM: degrees; } \\
\text { Short-form WOMAC } \\
(0-32) \text { : points }\end{array}$ & $\begin{array}{l}\text { Pre-test: the 3rd day } \\
\text { after TKA for WOMAC; } \\
\text { the } 2 \text { nd day after TKA } \\
\text { for other outcomes; } \\
\text { Post-test: the } 7 \text { th day } \\
\text { after TKA }\end{array}$ & $\begin{array}{l}\text { VAS } \downarrow ; \\
\text { ROM } \rightarrow ; \\
\text { WOMAC } \downarrow\end{array}$ \\
\hline Paravlic et al. [28] & Slovenia & Knee strength & Knee strength: Nm & $\begin{array}{l}\text { Pre-test: } 1 \text { day before } \\
\text { TKA; } \\
\text { Post-test: } 1 \text { month after } \\
\text { TKA }\end{array}$ & Knee strength $\uparrow$ \\
\hline Moukarzel et al [27] & France & $\begin{array}{l}\text { Knee strength; } \\
\text { Peak knee flexion dur- } \\
\text { ing the swing phase; } \\
\text { TUG; } \\
\text { OKS }\end{array}$ & $\begin{array}{l}\text { Knee strength: N/BMI; } \\
\text { ROM: degrees; } \\
\text { TUG: seconds; } \\
\text { OKS score: points }\end{array}$ & $\begin{array}{l}\text { Pre-test: } 6 \text { months after } \\
\text { TKA; } \\
\text { Post-test: } 4 \text { weeks after } \\
\text { the pre-test }\end{array}$ & $\begin{array}{l}\text { Knee strength } \uparrow ; \\
\text { Peak knee flexion during } \\
\text { the swing phase } \uparrow ; \\
\text { TUG } \rightarrow \text {; } \\
\text { OKS } \rightarrow\end{array}$ \\
\hline Moukarzel et al. [26] & France and Lebanon & $\begin{array}{l}\text { Pain evaluated by VAS; } \\
\text { Knee strength; } \\
\text { Knee flexion and exten- } \\
\text { sion ROM; } \\
\text { TUG }\end{array}$ & $\begin{array}{l}\text { VAS (0-100): mm; } \\
\text { Knee strength: N/BMl; } \\
\text { ROM: degrees; } \\
\text { TUG: seconds }\end{array}$ & $\begin{array}{l}\text { Pre-test: the beginning } \\
\text { of the first session after } \\
\text { TKA } \\
\text { Post-test: } 4 \text { weeks after } \\
\text { the pre-test }\end{array}$ & $\begin{array}{l}\text { VAS } \downarrow ; \\
\text { Knee strength } \uparrow ; \\
\text { Knee flexion and exten- } \\
\text { sion ROM } \uparrow ; \\
\text { TUG } \rightarrow\end{array}$ \\
\hline Zapparoli et al. [25] & Italy & $\begin{array}{l}\text { Pain evaluated by VAS; } \\
\text { Knee flexion and exten- } \\
\text { sion ROM; } \\
\text { TUG }\end{array}$ & $\begin{array}{l}\text { VAS (0-10): points; } \\
\text { ROM: degrees; } \\
\text { TUG: seconds }\end{array}$ & $\begin{array}{l}\text { Pre-test: entrance } \\
\text { rehabilitation unit } \\
\text { Post-test: } 11 \text { days after } \\
\text { the pre-test }\end{array}$ & $\begin{array}{l}\text { VAS } \downarrow ; \\
\text { Knee flexion and exten- } \\
\text { sion ROM } \uparrow ; \\
\text { TUG } \downarrow\end{array}$ \\
\hline
\end{tabular}

ROM: Range of motion; TUG: time up and go test; OKS: Oxford knee score; TKA: total knee arthroplasty; VAS: visual analogue scale; WOMAC: the Western Ontario McMaster Universities Osteoarthritis Index

observation on functional improvement with more studies, which was obviously advantageous for the improvement of arm function and arm performance in stroke patients. However, there was limited evidence about strength gains among musculoskeletal disorders [16]. To date, only one study supported the positive effect of MI after anterior cruciate ligament reconstruction [30]. In our study, we found that four out of six included studies supported the positive effect of MI, which has not been confirmed previously. We acquired a positive result probably because of different participants included. The result supported the clinical application of MI in TKA patients.

Our study concluded that MI took specific effect on pain relief, which was consistent with most of previous reviews. The efficacy of MI was evident for patients with acute pain after surgery [31]. Similarly, it was reported that MI and action observation could relieve pain after a knee or hip surgery [16]. However, a study supported the benefit of MI in chronic rather than acute musculoskeletal pain. It analyzed that acute pain originated from peripheral tissues, while chronic pain originated from central sensitization [14]. Given that the central sensitization is a process which develops from acute to chronic phase, MI still has a role in the acute musculoskeletal pain. Apart from MI, some randomized controlled trial (RCT) also studied other similar techniques. For example, enhanced reality could generate dose dependent synergistic analgesia among patients who underwent TKA. Two-week therapy was effective until 33 days after the therapy, while one-week therapy could last about twelve days only [32]. Furthermore, guided imagery that was applied 2 weeks before and 3 weeks after surgery could relieve pain in TKA patients [33]. All the above studies verified the importance of movement representation techniques. Movement representation techniques might be a potential analgesic technique in the rehabilitation after TKA. Just because of the small number of studies, it was impossible to give a definitive meta-analysis statement presently [34]. Therefore, future more studies of MI on improving pain after TKA should be necessary.

There are many indicators for TKA function assessment, including TUG, gait speed, 10-m walk test, OKS and WOMAC. Our summary result showed an improvement of TUG in MI-treated TKA patients, which was consistent with previous studies. Mental simulation practice, mainly the MI and action observation, was 


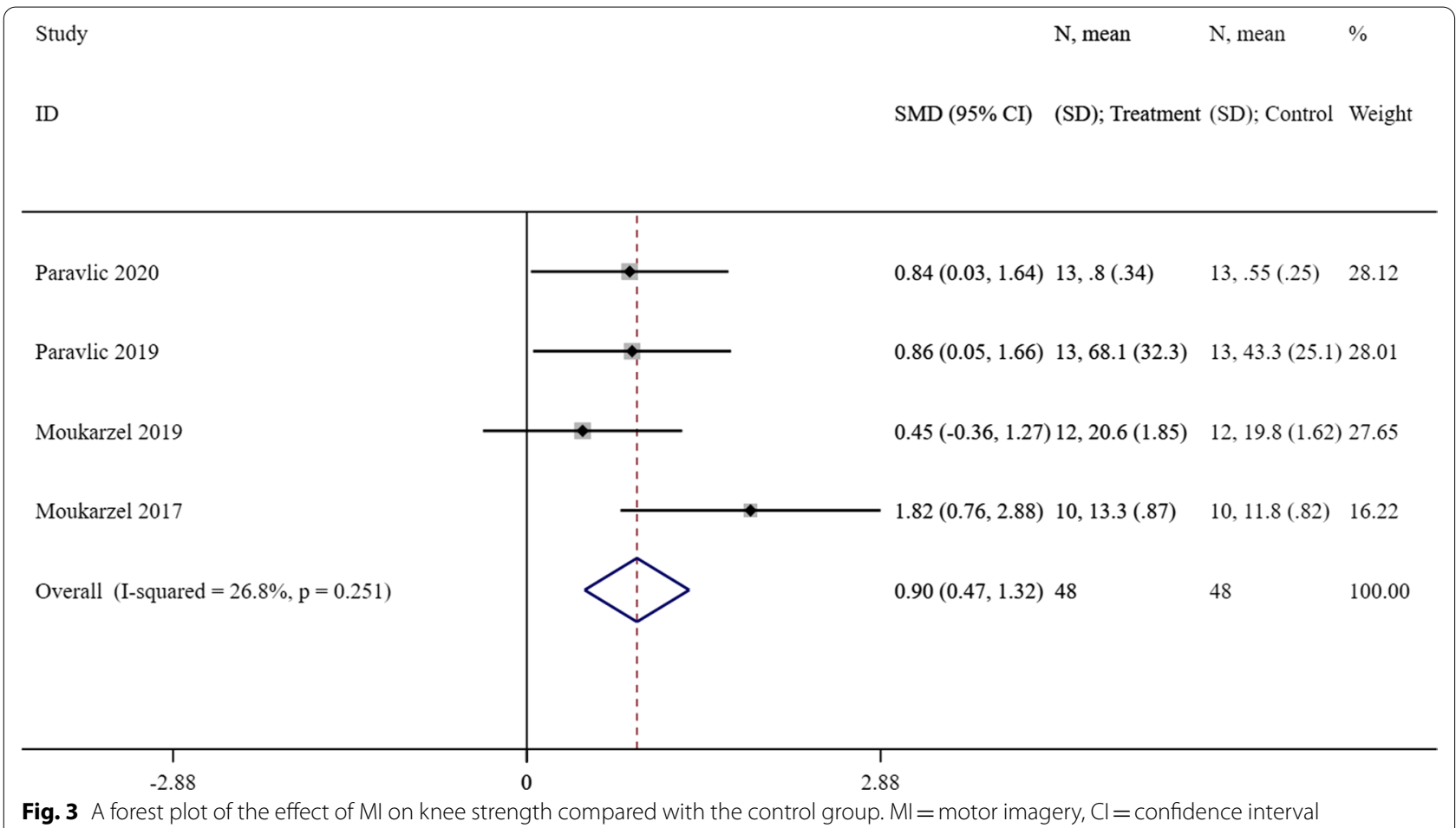

\begin{tabular}{|c|c|c|c|c|}
\hline Study & & $\mathrm{N}$, mean & $\mathrm{N}$, mean & $\%$ \\
\hline ID & $\operatorname{SMD}(95 \% \mathrm{CI})$ & (SD); Treatment & (SD); Control & Weight \\
\hline Paravlic 2020 & $-0.43(-1.21,0.35)$ & $13,31.5(12.1)$ & $13,37.3(14.7)$ & 24.30 \\
\hline Briones-Cantero 2020 & $-0.56(-1.38,0.26)$ & 12,30 & $12,39.5(19)$ & 22.04 \\
\hline Moukarzel 2017 & $-1.40(-2.38,-0.41)$ & $10,13.4(7.67)$ & $10,22.3(4.64)$ & 15.08 \\
\hline Zapparoli 2020 & $-1.21(-1.83,-0.60)$ & $24,1.71(1.73)$ & $24,4.65(2.96)$ & 38.58 \\
\hline Overall (I-squared $=25.4 \%, p=0.259$ ) & $-0.91(-1.29,-0.52)$ & 59 & 59 & 100.00 \\
\hline $\begin{array}{c}1 \\
-2.38\end{array}$ & 38 & & & \\
\hline
\end{tabular}

verified to have a positive effect on TUG and gait speed for lower limb arthroplasty patients [35]. It was worth noting that the use of MI could also improve TUG and gait speed for older adults when compared with the controls [36]. Based on the above two articles, MI should be useful for TKA patients. Due to few related articles, the 


\begin{tabular}{|c|c|c|c|c|}
\hline Study & & $\mathrm{N}$, mean & $\mathrm{N}$, mean & $\%$ \\
\hline ID & $\operatorname{SMD}(95 \% \mathrm{CI})$ & \multicolumn{2}{|c|}{ (SD); Treatment (SD); Control } & Weight \\
\hline Paravlic 2020 & \multicolumn{2}{|c|}{$-1.74(-2.65,-0.82) 13,7.55(1.22)$} & $13,11.5(3.01)$ & 16.94 \\
\hline Moukarzel 2019 & $-0.12(-0.92,0.68$ & $12,8.14(.63)$ & $12,8.21(.52)$ & 21.99 \\
\hline Moukarzel 2017 & $-0.23(-1.11,0.6$ & $10,12.7(2.76)$ & $10,13.3(2.66)$ & 18.23 \\
\hline Zapparoli 2020 & $-0.47(-1.04,0.16$ & $24,19(7.3)$ & $24,23(9.87)$ & 42.84 \\
\hline Overall (I-squared $=63.4 \%, p=0.042$ ) & $-0.56(-0.94,-0.1$ & 9)59 & 59 & 100.00 \\
\hline $\begin{array}{c} \\
-2.65\end{array}$ & & & & \\
\hline
\end{tabular}

Fig. 5 A forest plot of the effect of MI on TUG compared with the control group. MI= motor imagery, $T U G=$ time up and go test, $\mathrm{Cl}=$ confidence interval

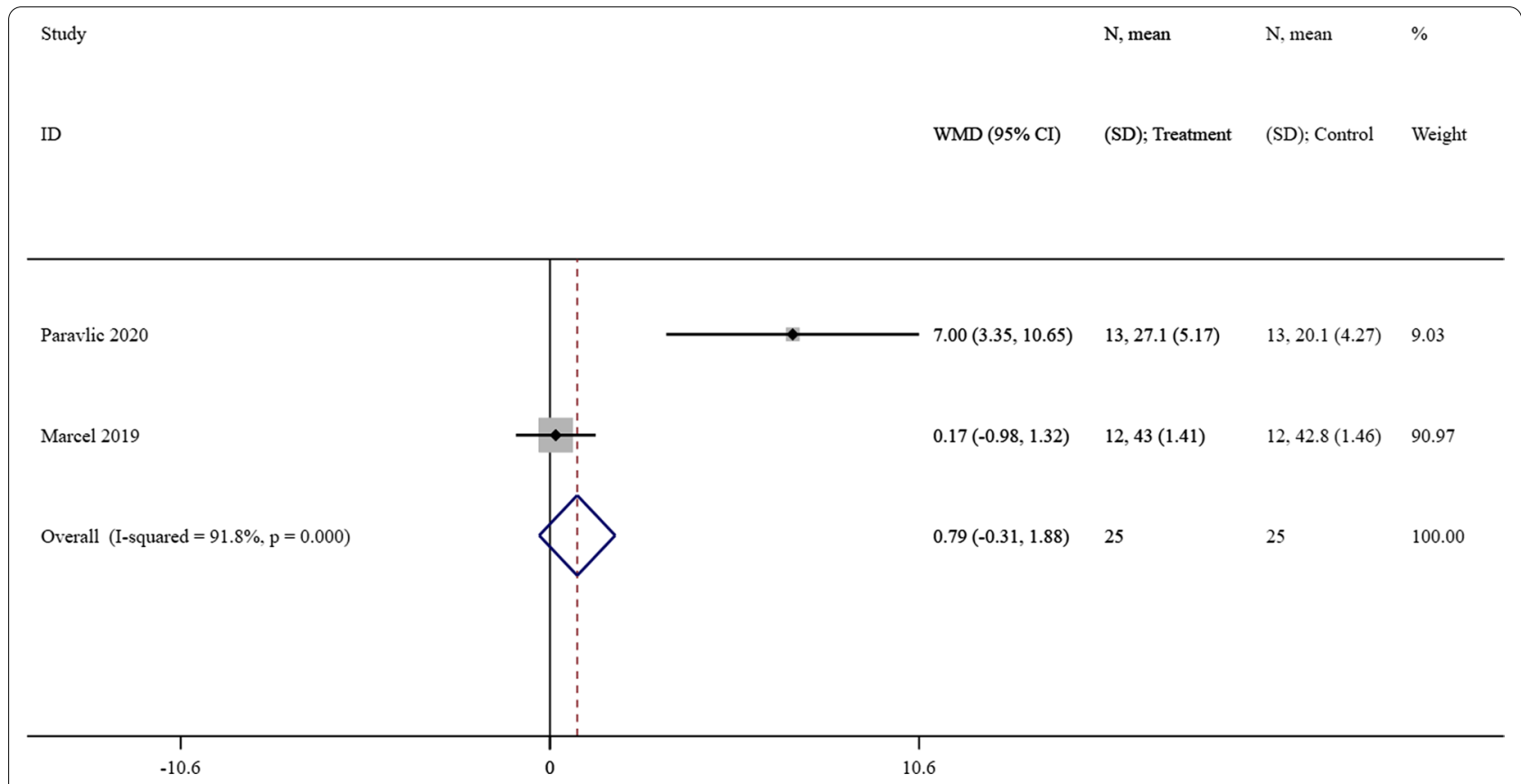

Fig. 6 A forest plot of the effect of $\mathrm{MI}$ on OKS compared with the control group. MI= motor imagery, OKS=Oxford Knee Score, $\mathrm{Cl}=$ confidence interval 
clinical significance of OKS and WOMAC change needs to be confirmed by more studies. Only a similar study supported action observation in improving WOMAC in patients with knee and hip arthroplasty [37]. It gave us a hint that researchers might prefer objective TUG and gait speed to subjective OKS and WOMAC. Anyway, MI played a positive role in the functional improvement of TKA patients according to current data.

There was little research about ROM till we finished the searching. A meta-analysis pointed out that MI with standard rehabilitation could bring a progress in ROM among chronic musculoskeletal pain rather than acute musculoskeletal pain. Further analysis found that kinesiophobia and edema might be the influence factors in acute phase which could not be regulated by MI [14]. No more articles were found except the above article [16]. Although the progress in ROM might be hindered by kinesiophobia, preoperative joint stiffness, or postoperative edema, our result would provide moderate evidence supporting MI in improving ROM among TKA patients. This was consistent with articles using other movement representation techniques. Two studies observed greater ROM in the action observation group for TKA patients in acute phase [37]. Another meta-analysis showed a moderate positive effect on the knee extension and flexion of the affected leg for patients with TKA or total hip arthroplasty [35]. A RCT study even found that the improvement of ROM could successfully maintain 33 days after the enhanced reality therapy for TKA patients in acute phase [32]. In conclusion, there are some positive results nowadays. More studies are needed to come to a more convincing conclusion about the role of $\mathrm{MI}$ in improving ROM in the future.

In brief, two main factors cause the dissatisfaction after TKA: the poor postoperative pain relief and the nonideal functional recovery. In order to improve postoperative recovery, increasing training intensity has become the common rehabilitation means, which leads to excessive pain in turn. According to our results, MI can perfectly solve the contradiction between increasing exercise intensity and excessive pain. MI can be regarded as a new way to improve the prognosis of TKA.

Some limitations must be mentioned. First, there were limited available articles about MI implementation among the TKA patients. More large-scale, prospective researches are needed in the future. Second, because of the limited available studies, in the inclusion criteria, there were no specific requirements about the operation method. If more studies could be obtained, subgroup analysis such as revision surgery and TKA after unicompartmental knee arthroplasty must be considered. Third, only articles in English were included. Some relevant studies may be missed.

\section{Conclusion}

To our knowledge, this is the first systematic review with meta-analysis about the effect of MI on functional recovery after TKA. Existing evidence showed a promising conclusion. The MI was beneficial to strength enhancement, pain reduction and TUG decrease. After combining all the results presented by different evaluation criteria, MI also seemed to be advantageous to ROM increase. The effect of MI on OKS and WOMAC was uncertain due to the deficiency of relevant studies. Given the evidence in this study, MI has great potential to improve the longterm prognosis of TKA without excessive pain.

\section{Abbreviations}

MD: Mean differences; SMD: Standard mean differences; Cl: Confidence intervals; TKA: Total knee arthroplasty; MI: Motor imagery; WOMAC: Western Ontario and McMaster Universities Osteoarthritis Index; ROM: Range of motion; PRISMA: Preferred reporting items for systematic reviews and metaanalyses; VAS: Visual Analogue Scale; BMI: Body mass index; TUG: Time up and go test; OKS: Oxford Knee Score; RCT: Randomized controlled trial; MViC: Maximal voluntary isometric contraction.

\section{Supplementary Information}

The online version contains supplementary material available at https://doi. org/10.1186/s13018-022-02946-4.

Additional file 1. PRISMA-2020 checklist.

\section{Acknowledgements}

Not applicable.

\section{Authors' contributions}

Conceptualization: LR and DJB; Data collection: WX and WWJ; Data analysis: YK and LR; Data interpretation: LR, YK and DJB; Manuscript preparation: LR; Manuscript revision: YK and DJB. All authors read and approved the final manuscript.

\section{Funding}

This work was funded by Beijing Excellent Talents Foundation (No. 2018000020124G141). The funders played no role in the design, conduct, or reporting of this study.

\section{Availability of data and materials}

The datasets used and/or analyzed during the current study are available from the corresponding author on reasonable request.

\section{Declarations}

Ethics approval and consent to participate Not applicable.

\section{Consent for publication}

Not applicable.

\section{Competing interests}

The authors declare that they have no competing interests.

\section{Author details}

${ }^{1}$ Department of Rehabilitation Medicine, Xuanwu Hospital, Capital Medical University, 45\# Chang Chun Street, Beijing 100000, China. ${ }^{2}$ Department of Rehabilitation Center, Fuxing Hospital, Capital Medical University, 20\# Fu Xing Men Wai Street, Beijing 100000, China. 
Received: 3 November 2021 Accepted: 21 January 2022

Published online: 02 February 2022

\section{References}

1. Legrand T, Equey N, Younesian H, Campeau-Lecours A, Turcot K. Impact of a combination of functional adaptations on the lower limb joints using a visual feedback approach. Gait Posture. 2020;81:208-9.

2. Beswick AD, Wylde V, Gooberman-Hill R, Blom A, Dieppe P. What proportion of patients report long-term pain after total hip or knee replacement for osteoarthritis? A systematic review of prospective studies in unselected patients. BMJ Open. 2012;2(1):e000435.

3. Gunaratne R, Pratt DN, Banda J, Fick DP, Khan RJK, Robertson BW. Patient dissatisfaction following total knee arthroplasty: a systematic review of the literature. J Arthroplasty. 2017;32(12):3854-60.

4. Khatib Y, Badge H, Xuan W, Naylor JM, Harris IA. Patient satisfaction and perception of success after total knee arthroplasty are more strongly associated with patient factors and complications than surgical or anaesthetic factors. Knee Surg Sports Traumatol Arthrosc. 2020;28(10):3156-63.

5. Tripathy SK, Varghese P, Srinivasan A, Goyal T, Purudappa PP, Sen RK, et al. Joint awareness after unicompartmental knee arthroplasty and total knee arthroplasty: a systematic review and meta-analysis of cohort studies. Knee Surg Sports Traumatol Arthrosc. 2020;29(10):3478-87.

6. Moukarzel M, Rienzo FD, Lahoud JC, Hoyek F, Collet C, Guillot A, et al. The therapeutic role of motor imagery during the acute phase after total knee arthroplasty: a pilot study. Disabil Rehabil. 2017;41:926-33.

7. Robbins SM, Rastogi R, Mclaughlin TL. Predicting acute recovery of physical function following total knee joint arthroplasty. J Arthroplasty. 2014;29(2):299-303.

8. Castrodad IMD, Recai TM, Abraham MM, Etcheson JI, Mohamed NS, Edalatpour A, et al. Rehabilitation protocols following total knee arthroplasty: a review of study designs and outcome measures. Ann Transl Med. 2019;7(Suppl 7):S255.

9. Mistry JB, Elmallah RDK, Bhave A, Chughtai M, Cherian JJ, Mcginn T, et al. Rehabilitative guidelines after total knee arthroplasty: a review. J Knee Surg. 2016;29(3):201-17.

10. Rodríguez-Merchán EC. The stiff total knee arthroplasty: causes, treatment modalities and results. EFORT Open Rev. 2019:4(10):602-10.

11. Vandell RA, Davis RA, Clugston HA. The function of mental practice in the acquisition of motor skills. J Gen Psychol. 1943;29(2):243-50.

12. Li RQ, Li ZM, Tan JY, Chen GL, Lin WJ. Effects of motor imagery on walking function and balance in patients after stroke: a quantitative synthesis of randomized controlled trials. Complement Ther Clin Pract. 2017;28:75-84.

13. Guerra ZF, Lucchetti ALG, Lucchetti G. Motor imagery training after stroke: a systematic review and meta-analysis of randomized controlled trials. J Neurol Phys Ther Jnpt. 2017;41(4):205-14.

14. Yap BWD, Lim ECW. The effects of motor imagery on pain and range of motion in musculoskeletal disorders: a systematic review with metaanalysis. Clin J Pain. 2019;35(1):87-99.

15. Gurudut P, Jaiswal R. Comparative effect of graded motor imagery and progressive muscle relaxation on mobility and function in patients with knee osteoarthritis: a pilot study. Altern Ther Health Med. 2020; AT6436.

16. Suso-Martí L, La Touche R, Angulo-Díaz-Parreo S, Cuenca-Martínez F. Effectiveness of motor imagery and action observation training on musculoskeletal pain intensity: a systematic review and meta-analysis. Eur J Pain. 2020;24(5):886-901.

17. Marusic U, Grosprêtre S, Paravlic A, Kovač S, Pišot R, Taube W. Motor imagery during action observation of locomotor tasks improves rehabilitation outcome in older adults after total hip arthroplasty. Neural Plast. 2018;2018:5651391.

18. Grosprêtre S, Ruffino C, Lebon F. Motor imagery and cortico-spinal excitability: A review. Eu J Sport Sci EJSS. 2016;16(3):317-24.

19. Ruffino C, Papaxanthis C, Lebon F. Neural plasticity during motor learning with motor imagery practice: review and perspectives. Neuroscience. 2017:341:61-78

20. Yao WX, Ranganathan VK, Allexandre D, Siemionow V, Yue GH. Kinesthetic imagery training of forceful muscle contractions increases brain signal and muscle strength. Front Hum Neurosci. 2013;7:561.
21. Page MJ, McKenzie JE, Bossuyt PM, Boutron I, Hoffmann TC, Mulrow CD, et al. The PRISMA 2020 statement: an updated guideline for reporting systematic reviews. Syst Rev. 2021;372:n71.

22. Higgins JPT, Thomas J, Chandler J, Cumpston M, Li T, Page MJ, et al. Cochrane handbook for systematic reviews of interventions version 6.2 Cochrane. 2021

23. Briones-Cantero M, Fernández-de-Las-Peñas $C$, Lluch-Girbés E, OsunaPérez MC, Navarro-Santana MJ, Plaza-Manzano G, et al. Effects of adding motor imagery to early physical therapy in patients with knee osteoarthritis who had received total knee arthroplasty: a randomized clinical trial. Pain Med. 2020;21(12):3548-55.

24. Paravlic AH, Maffulli N, Kovač S, Pisot R. Home-based motor imagery intervention improves functional performance following total knee arthroplasty in the short term: a randomized controlled trial. J Orthop Surg Res. 2020;15(1):451.

25. Zapparoli L, Sacheli LM, Seghezzi S, Preti M, Paulesu E. Motor imagery training speeds up gait recovery and decreases the risk of falls in patients submitted to total knee arthroplasty. Sci Rep. 2020;10(1):8917.

26. Moukarzel M, Di Rienzo F, Lahoud JC, Hoyek F, Collet C, Guillot A, et al. The therapeutic role of motor imagery during the acute phase after total knee arthroplasty: a pilot study. Disabil Rehabil. 2017;41 (8):926-33.

27. Moukarzel M, Guillot A, Di Rienzo F, Hoyek N. The therapeutic role of motor imagery during the chronic phase after total knee arthroplasty: a pilot randomized controlled trial. Eur J Phys Rehabil Med. 2019;55(6):806-15.

28. Paravlic AH, Pisot RUM. Specific and general adaptations following motor imagery practice focused on muscle strength in total knee arthroplasty rehabilitation: A randomized controlled trial. PLOS ONE. 2019;14(8):e0221089.

29. Paravlic AH, Slimani M, Tod D, Marusic U, Milanovic Z, Pisot R. Effects and dose-response relationships of motor imagery practice on strength development in healthy adult populations: a systematic review and meta-analysis. Sports Med. 2018:48(5):1165-87.

30. Pastora-Bernal JM, Estebanez-Pérez MJ, Lucena-Anton D, García-López FJ, Bort-Carballo A, Martín-Valero R. The effectiveness and recommendation of motor imagery techniques for rehabilitation after anterior cruciate ligament reconstruction: a systematic review. J Clin Med. 2021;10(3):428.

31. Thieme H, Morkisch N, Rietz C, Dohle C, Borgetto B. The efficacy of movement representation techniques for treatment of limb pain-a systematic review and meta-analysis. J Pain. 2016;17(2):167-80.

32. Koo KI, Park DK, Youm YS, Cho SD, Hwang C. Enhanced reality showing long-lasting analgesia after total knee arthroplasty: prospective, randomized clinical trial. Sci Rep. 2018;8(1):2343.

33. Jacobson AF, Umberger WA, Palmieri PA, Alexander TS, Myerscough RP, Draucker CB, et al. Guided imagery for total knee replacement: a randomized, placebo-controlled pilot study. J Altern Complement Med. 2016;22(7):563-75.

34. Whale K, Wylde V, Beswick A, Rathbone J, Vedhara K, Gooberman-Hill R. Effectiveness and reporting standards of psychological interventions for improving short-term and long-term pain outcomes after total knee replacement: a systematic review. BMJ Open. 2019;9(12):e029742.

35. Paravlic AH, Tod D, Milanovic Z. Mental simulation practice has beneficial effects on patients' physical function following lower limb arthroplasty: a systematic review and meta-analysis. Arch Phys Med Rehabil. 2020;101(8):1447-61.

36. Nicholson V, Watts N, Chani Y, Keogh JW. Motor imagery training improves balance and mobility outcomes in older adults: a systematic review. J Physiother. 2019;65(4):200-7.

37. Ryan D, Fullen B, Rio E, Segurado R, Stokes D, O'Sullivan C. Effect of action observation therapy in the rehabilitation of neurologic and musculoskeletal conditions: a systematic review. Arch Rehabil Res Clin Transl. 2021:3(1):100106.

\section{Publisher's Note}

Springer Nature remains neutral with regard to jurisdictional claims in published maps and institutional affiliations. 